\title{
The long winding road of opioid substitution therapy implementation in South-East Asia: challenges to scale up
}

\author{
Gary Reid, ${ }^{1}$ Mukta Sharma, ${ }^{2}$ Peter Higgs ${ }^{3,4}$ \\ ${ }^{1}$ Independent Consultant HIV/AIDS, New Delhi, India; ${ }^{2}$ World Health Organization, Thailand \\ Country Office, Nonthaburi, Thailand; ${ }^{3}$ National Drug Research Institute, Faculty of Health \\ Sciences, Curtin University, Australia; ${ }^{4}$ Burnet Institute, Melbourne, Australia
}

\begin{abstract}
Significance for public health
Several countries in the World Health Organization South-East Asia Region can be commended for introducing opioid substitution therapy (OST) to address the ongoing HIV epidemic among people who inject drugs (PWID). Local evidence shows OST is an effective drug treatment approach in the Asian context given sufficient technical and institutional support. However, despite much progress, the number of OST dispensing sites and recipients remains totally inadequate in terms of impact upon the current HIV epidemic among PWID. Ongoing advocacy is needed if countries are to achieve the WHO's target of 40\% of PWID being dosed with OST. Greater political commitment a strengthened policy environment, capacity building for OST clinics, lessening the criminalisation of drug use and promoting a public health response will give many more PWID access to OST and slow the advance of the HIV epidemic.
\end{abstract}

\section{Abstract}

The South-East Asia Region contains an estimated 400,000-500,000 people who inject drugs (PWID). HIV prevalence among PWID is commonly $20 \%$ or higher in Indonesia, Thailand, Myanmar and some regions of India. Opioid substitution therapy (OST) is an important HIV prevention intervention in this part of the world. However, key challenges and barriers to scale up of OST exist, including: pervasive stigma and discrimination towards PWID; criminalisation of drug use overshadowing a public health response; lack of political will and national commitment; low financial investment; focus towards traditional treatment models of detoxification and rehabilitation; inadequate dosing of OST; and poor monitoring and evaluation of programmes. Our review of local evidence highlights that OST can be successful within the Asian context. Such evidence should be utilised more widely to advocate for policy change and increased political commitment to ensure OST reaches substantially more drug users.

\section{Background}

Global estimates indicate that there are 15.9 million (range 11.021.2 million) people who inject drugs (PWID) across 151 countries., ${ }^{1,2}$ Of these, approximately three million (range 0.8-6 million) PWID are HIV infected. ${ }^{1}$ Furthermore, it is estimated that 10 per cent of all new HIV infections can be attributed to injecting drugs, rising to 30 per cent when sub-Saharan Africa is excluded. ${ }^{3}$ Within what the World Health Organization (WHO) define as their South-East Asia Region (SEAR) there are an estimated 400,000-500,000 PWID, ${ }^{4}$ primarily located in countries that experience a high or medium burden of illic- it drug injecting (WHO Office for SEAR covers 11 countries: Bangladesh, Bhutan, DPR Korea, India, Indonesia, Maldives, Myanmar, Nepal, Sri Lanka, Thailand and Timor-Leste).

Data from several sources show that high risk behaviours among PWID are common and provision of comprehensive HIV prevention services varies (Table 1). HIV prevalence among PWID in South-East Asia was commonly identified at $20-25 \%$ and has remained consistently high in Indonesia, Nepal, Thailand, Myanmar and some regions of India. ${ }^{5}$ Whilst a decline was recorded in HIV prevalence among Nepalese PWID, from 68\% in 2002 to $21 \%$ in 2009 and 6\% in $2011,{ }^{6-8}$ HIV prevalence rose in Bangladeshi PWID, from 4\% in 2003-2004 to 7\% in $2007,{ }^{9}$ and in Punjab (India) from $13 \%$ in 2006 to $21 \%$ in $2011 .{ }^{10}$ High-risk behaviours among PWID, such as the sharing of contaminated needles and syringes, remain a major determining factor in the course of the HIV epidemic throughout Asia. ${ }^{11-13}$

The ongoing HIV epidemic among PWID in South-East Asia has prompted many countries to develop HIV policies linked to national HIV strategic plans in which harm reduction interventions are increasingly viewed with understanding and acceptance. ${ }^{4}$ UNAIDS UNDOC and WHO outline nine interventions as part of a comprehensive package that has the greatest impact on HIV prevention, treatment and care for PWID. ${ }^{14}$ Meta-analysis and systematic reviews show conclusively that providing opioid substitution therapy (OST) together with needle and syringe programmes and antiretroviral treatment targeted towards PWID have the greatest effect in preventing HIV infection. ${ }^{15}$

In this article the focus is upon one essential harm reduction intervention, OST, and its use in countries that fall under the administrative purview of WHO's SEAR, with specific focus on Bangladesh, India, Indonesia, Maldives, Myanmar, Nepal and Thailand. We excluded Timor-Leste, Bhutan and the Democratic People's Republic of Korea due to limited data.

Methadone has been prescribed for the treatment of opioid dependency for over four decades and buprenorphine has been available since the early 2000s. Both were added to the WHO list of essential medicines in 2005 , and are usually consumed orally or sublingually as maintenance treatment to relieve opioid withdrawal and to reduce cravings. Research has shown them to be effective in the reduction of HIV risk behaviours and other comorbidities. ${ }^{16,17}$ Due to the chronic nature of opioid dependency, treatment outcomes are better in long-term therapy incorporating adequate dosing (at least $60 \mathrm{mg}$ of methadone and 8$6 \mathrm{mg}$ buprenorphine per day). ${ }^{16}$

Despite the strong evidence for various benefits resulting from the use of OST - improved retention in treatment for HIV, HCV and opioid use, ${ }^{16}$ reduced illicit opioid use, ${ }^{17}$ reduced risk of HIV, ${ }^{18}$ reduced criminality, better psychosocial outcomes and decreased risk to pregnant drug-dependent women ${ }^{19}$ (during the intra-uterine, partum and postpartum period ${ }^{20}$ ) fewer than three per cent of PWID in the South-East Asia Region have access to OST. ${ }^{12}$ In this article we explore the histor- 
ical adoption of OST, the current situation, some of the major challenges, and suggest ways to scale up OST in the SEAR.

\section{Methods}

We reviewed published and grey literature located using Medline and PubMed, WHO program documents for the countries of the SEAR, the Joint United Nations Programme on HIV/AIDS (UNAIDS), the United Nations Office on Drugs and Crime (UNODC) documents, and generic internet search engines between October 2011 and June 2013. Direct email requests were made to WHO HIV country focal points and official government counterparts for additional data and comments about OST in the SEAR between September 2010 and March 2013.

\section{Results}

\section{Implementation of opioid substitution therapy}

The amount and quality of the data available on the commencement of OST programmes, responsible agencies, the number of PWID receiving OST, and the linkages with other health and non-health systems vary considerably among the countries in South-East Asia (Table 2).

Nepal started a government-approved methadone-based OST programme in $1994 .{ }^{21}$ Despite satisfactory outcomes, the programme was suspended in 1998, and then restarted as an emergency response for HIV prevention in September 2007. ${ }^{4}$ In India, sublingual buprenorphine treatment commenced in 1993 as a pilot project and has been licensed for treatment of opioid dependence in drug treatment centres since 1999. ${ }^{22,23}$ Methadone maintenance therapy (MMT) commenced in India in $2011 .^{24}$

In Thailand, limited methadone treatment became available in 1979, primarily as a detoxification program in approved clinics. In 1989 a national clinical trial of MMT was initiated. MMT started in Bangkok as an HIV prevention measure in 1990, and gradually extended to a few clinics outside the capital. ${ }^{25,26}$ Buprenorphine was approved for opioid treatment in 2007, and a trial of buprenorphine-naloxone was initiated in Chiang Mai during the same year, but it is not routinely used in opioid treatment programs. ${ }^{26}$

Buprenorphine was introduced in Indonesia in 2001, and the manufacturers of the drug encouraged private practitioners to prescribe the medication to drug-dependent clients. ${ }^{27,28}$ In 2003 the Indonesian Ministry of Health established MMT (with technical and financial assistance from WHO) in two pilot projects, one in Jakarta and one in a joint pilot within a Bali prison and a hospital. These two pilots continued until the end of 2005 , serving a population of approximately 300 drug users. ${ }^{29}$

Preparation for the introduction of methadone began in Myanmar in 2004, with the Ministry of Health commencing the delivery of MMT over February and March 2006 in four drug treatment centres. Around 2900 clients were receiving MMT by $2013 .{ }^{30}$

In November 2008, MMT was introduced into the Maldives as part of a pilot study; ${ }^{31}$ buprenorphine remained unavailable due to its classification as an illegal substance. ${ }^{4}$

\section{Opioid substitution therapy availability in 2009-2012}

In Nepal, as of June 2011, 380 clients were receiving methadone from three sites in the cities of Kathmandu, Patan and Pokhara (Kramarz P., 2011; personal communication). The demand for methadone was reported to be high, with a long waiting list to join the programme. In Pokhara, 88 PWID were enrolled to receive methadone and 62 were active recipients. ${ }^{32}$ In 2009, 30 Nepalese PWID received buprenorphine administered as part of a three-month tapering reduction dose rather than long-term maintenance therapy. ${ }^{12}$ At the end of 2010, NG0s were dispensing buprenorphine from six sites to 175 clients. The three-month duration of treatment of 2-4 mg per day remained unchanged. Take-home/home delivery of buprenorphine was only granted under exceptional circumstances (Pandey B., 2010; personal communication). The provision of buprenorphine is not currently an official part of the government OST programme.

Initial Indian targets were for 40,000 PWID to receive OST by 2012, with delivery through 320 sites, primarily NGOs or government-run treatment centres. ${ }^{4}$ By May 2011, buprenorphine was available from 52 sites and 4810 clients were in treatment; data from December 2012 show that 120 buprenorphine sites were delivering treatment to 7500 regular patients (in India regular patients are defined as those accessing OST 24 days or more per month; those that received less frequent treatment are not included). ${ }^{30}$

Apart from small pilot studies Methadone has not been available for clinical use in India following its removal from the Indian pharmacopoeia in $1982 .{ }^{33}$ However, in early 2010 the government approved the use of methadone in a pilot study intended to involve six sites in late 2010. By 2012 four methadone dispensing sites were servicing 350 patients (Kumar R. 2013; personal communication). A buprenorphine project commenced inside Tihar prison, New Delhi in late 2008, but client numbers remain small.

In 2009 the Bangkok Metropolitan Administration funded 20 methadone clinics at two hospitals and 18 health centres, ${ }^{34}$ and across Thailand an estimated 4000-5000 patients were receiving methadone. ${ }^{12}$ In 2010, 2200 patients received methadone treatment, but probable duplication of some client records makes this number uncertain, and whether they were receiving long-term treatment is undetermined (Thanpresertsuk S., 2011; personal communication). The reasons for the apparent fall in client numbers between 2009 and 2010 are unknown (the 2009 figures are estimates only), although the general shift from opioid use to stimulant use in Thailand is likely to have contributed. In 2012, 147 sites were dispensing methadone to 2777 patients..$^{30}$ Methadone is the National Health Security Office's approved OST medication and was placed on the Thai Essential Drug List in 2008; it is available as part of the Universal Health Coverage package for all Thai citizens. In 2009, an estimated 150 clients were reported to be receiving buprenorphine as part of an HIV prevention trial at Chiang Mai University, which has since been completed. ${ }^{4,12}$

In Indonesia, methadone expansion began in 2006 with seven clinics serving 1000 clients by the end of that year. ${ }^{29}$ By April 2010 methadone was available in ten provinces from 51 clinics (five specialist hospitals; 10 general hospitals; 30 primary health centres; and six prison and detention centres) (Sarasvita R., 2010; personal communication). In June 2011, Indonesia had 68 government-funded clinics with 2540 active patients. In addition, more than 50 medical prescribers in private practices were dispensing buprenorphine to an estimated 3000 patients. ${ }^{35}$

In Myanmar in January 2010, 821 patients were receiving methadone from eight sites in four states, ${ }^{3}$ and by June 2011 patient numbers had increased to $1087 .^{36}$ In late 2012,13 methadone sites were dispensing to 2909 patients. ${ }^{30,37}$ Methadone was dispensed from drug treatment centres as part of Global Fund Round. ${ }^{9}$

In the Maldives, 47 patients had been enrolled to receive methadone in late $2009,{ }^{4}$ but by April 2010 only 17 patients remained, decreasing to 11 by August 2010 (Mohamed A.J., 2010; personal communication); by July 2011 patient numbers had rebounded to 57 (Aminath Z., 2011; personal communication). Barriers to methadone programme enrolment in the Maldives include the need to obtain clearance from five dif- 
Table 1. HIV prevalence among people who inject drugs in selected South-East Asia Region countries: interventions, behaviours and reach of HIV prevention programmes 2009-2012.

\begin{tabular}{|c|c|c|c|c|c|c|}
\hline Country & $\begin{array}{l}\text { Estimated } \\
\text { number } \\
\text { of PWID }\end{array}$ & $\begin{array}{l}\text { Estimated HIV } \\
\text { prevalence } \\
(\%)\end{array}$ & $\begin{array}{l}\text { Harm } \\
\text { reduction } \\
\text { interventions } \\
\text { adopted as policy } \\
\text { for PWID (n.) }\end{array}$ & $\begin{array}{l}\text { PWID report using } \\
\text { sterile injecting } \\
\text { equipment last time } \\
\text { of injecting (\%) }\end{array}$ & $\begin{array}{l}\text { PWID reporting } \\
\text { use of } \\
\text { condoms last } \\
\text { having sexual } \\
\text { intercourse (\%) }\end{array}$ & $\begin{array}{l}\text { PWID reached with } \\
\text { HIV } \\
\text { prevention } \\
\text { programmes (\%) }\end{array}$ \\
\hline Bangladesh & $21,800-23,800$ & 7 Dhaka & 9 & $\begin{array}{l}33.6 \text { (male) } \\
73.8 \text { (female) }\end{array}$ & 30.2 & 2.1 \\
\hline India & $177,000-180,000$ & 7 & 9 & $29-88$ & $44-100$ & $10-83$ \\
\hline Indonesia & $\begin{array}{l}105,784 \\
(73,663-201,131)\end{array}$ & 36 & 9 & 88.3 & 35.7 & 43.38 \\
\hline Maldives & $793(690-896)$ & 0 & 6 & $69-77$ & 6 & Not available \\
\hline Myanmar & 75,000 & 22 & 9 & 81 (last month) & 78 & 8274 \\
\hline Nepal & $17,000-24,000$ & 6 Kathmandu & 8 & 50.8 & 99 & 56.9 \\
\hline Thailand & 40,300 & 22 & 9 & $<50$ & $<40$ & Not available \\
\hline
\end{tabular}

Source: WHO, UNAIDS, UNODC, UNGASS reports and Harm Reduction International (Global State of Harm Reduction Towards An Integrated Response 2012). PWID, people who inject drugs.

Table 2. Opioid substitution therapy in selected South-East Asia Region countries: start date, numbers, linkages, compulsory/court mandated, modality.

\begin{tabular}{|c|c|c|c|c|c|c|c|c|}
\hline Country & $\begin{array}{l}\text { Year first } \\
\text { trialled, } \\
\text { started } \\
\text { OST }\end{array}$ & $\begin{array}{l}\text { Key responsible } \\
\text { agencies } \\
\text { for OST }\end{array}$ & $\begin{array}{l}\text { No. OST } \\
\text { sites } \\
(2010-2012)\end{array}$ & $\begin{array}{l}\text { No. receiving } \\
\text { OST } \\
(2009-2012)\end{array}$ & $\begin{array}{l}\text { OST service } \\
\text { links with other } \\
\text { health services }\end{array}$ & $\begin{array}{l}\text { OST service } \\
\text { has links with } \\
\text { non-health } \\
\text { services }\end{array}$ & $\begin{array}{l}\text { Compulsory or } \\
\text { court mandated } \\
\text { treatment } \\
\text { exists }\end{array}$ & $\begin{array}{l}\text { Modality of } \\
\text { OST } \\
\text { delivery }\end{array}$ \\
\hline Bangladesh & $2010-M$ & $\begin{array}{l}\text { ICDDR,B with } \\
\text { funding support } \\
\text { from UNODC }\end{array}$ & $2-M$ & 188 & $\begin{array}{l}\text { Based in govt detox } \\
\text { clinic, where several } \\
\text { psychiatrists provide } \\
\text { support as and when } \\
\text { needed. The OST } \\
\text { clinic is also linked to } \\
\text { ICDDR, B voluntary } \\
\text { counseling testing unit }\end{array}$ & $\begin{array}{l}\text { No - but plans } \\
\text { underway }\end{array}$ & No & Government \\
\hline India & $\begin{array}{l}1993-B \\
2011-M\end{array}$ & $\begin{array}{l}\text { MoH, Ministry of } \\
\text { Social Justice, } \\
\text { Empowerment, } \\
\text { \& National AIDS } \\
\text { Control Office }\end{array}$ & $\begin{array}{l}120-B \\
4-M\end{array}$ & $\begin{array}{l}7500-B \\
350-M\end{array}$ & Weak to good links & Weak to good links & No & $\begin{array}{l}\text { Government } \\
\& \text { NGO }\end{array}$ \\
\hline Indonesia & $\begin{array}{l}2001-B \\
2003-M\end{array}$ & $\begin{array}{l}\text { MoH for methadone. } \\
\text { Private practitioners } \\
\text { dispense } \\
\text { buprenorphine } \\
\text { following training } \\
\text { Largely } \\
\text { unsupervised by Moh }\end{array}$ & $\begin{array}{l}68-\mathrm{M} \\
?-\mathrm{B} \\
\text { (50 doctors } \\
\text { trained in } \\
\text { buprenorphine } \\
\text { dispensing }\end{array}$ & $\begin{array}{l}2540-\mathrm{M} \\
3000 \mathrm{~B}\end{array}$ & Weak links & Weak Links & No & $\begin{array}{l}\text { Government } \\
\text { \& Private }\end{array}$ \\
\hline Maldives & $2008-M$ & Moh & $1-M$ & $57-\mathrm{M}$ & No & No & No & Government \\
\hline Myanmar & $2004-M$ & $\begin{array}{l}\text { Department of } \\
\text { Health - medical } \\
\text { care }\end{array}$ & $13-\mathrm{M}$ & $1637-M$ & Weak to good links & Weak to good links & Yes & Government \\
\hline Nepal & $1994-\mathrm{M}$ & $\begin{array}{l}\text { Ministry of Home } \\
\text { Affairs, UNODC, } \\
\text { Hospitals, NGOs } \\
\text { (not part of official } \\
\text { government programs }\end{array}$ & $3-\mathrm{M}$ & $\begin{array}{l}386-\mathrm{M} \\
175-\mathrm{B}\end{array}$ & $\begin{array}{l}\text { Overall weak links } \\
\text { but some sites have } \\
\text { good links but with } \\
\text { constraints }\end{array}$ & $\begin{array}{l}\text { Overall weak links } \\
\text { but some sites } \\
\text { have good links }\end{array}$ & No & $\begin{array}{l}\text { Government } \\
\& \mathrm{NGO}\end{array}$ \\
\hline Thailand & $\begin{array}{l}1979-M \\
2007-B\end{array}$ & $\begin{array}{l}\text { Thanyarak Institute } \\
\text { of the Department } \\
\text { of Medical Services, } \\
\text { under the Ministry } \\
\text { of Public Health }\end{array}$ & $\begin{array}{l}147-M \\
?-B\end{array}$ & $\begin{array}{l}1183-M \\
?-B\end{array}$ & $\begin{array}{l}\text { Fully integrated } \\
\text { (most OST services } \\
\text { attached within health } \\
\text { care settings) }\end{array}$ & Weak links & Yes & $\begin{array}{l}\text { Regional drug } \\
\text { treatment } \\
\text { centers (of the } \\
\text { Department of } \\
\text { Medical } \\
\text { Services) \& } \\
\text { Govt Hospitals }\end{array}$ \\
\hline
\end{tabular}

OST, opioid substitution therapy; B, Buprenorphine; M, Methadone; ICDDR,B, International Centre for Diarrhoeal Disease Research, Bangladesh; MoH, Ministry of Health. 
ferent government departments to ensure no criminal cases are pending. It is reported that the methadone programme functions well, but scope for improvement remains. ${ }^{38}$

In July 2010, after several years of advocacy to initiate OST, Bangladesh commence methadone provision, starting with one site in Dhaka. By early 2013 an additional site had opened and 188 clients were receiving methadone (Azim T., 2013; personal communication).

\section{Challenges and barriers to scale up of opioid substitution therapy}

Various common challenges and barriers exist to the implementation and expansion of OST services. Throughout the region drug users continue to experience high levels of stigma and discrimination due to their substance use. This impacts upon the delivery of general health services, including access to OST. ${ }^{39-41}$ In the UK it has been noted that key government policies to assist PWID reintegration and recovery through the use of OST were highly unlikely to succeed while stigmatising attitudes towards PWID remain pervasive. ${ }^{42}$ Stigma and discrimination remain major barriers across South-east Asia.

Acknowledging drug use and responding to HIV risk-taking behaviour was largely delayed across Asia in comparison to many Western countries, ${ }^{43,44}$ and the criminalisation of drug use still commonly overshadows a public health response to address this problem. ${ }^{45}$ Various countries in the SEAR force drug users into compulsory drug detention centres. Official reports state that 235,000 people were detained in over 1000 compulsory drug detention centres in East and South East Asia alone in 2012. Since 2012, many United Nation agencies have called for their closure for reasons including human rights abuses and a lack of evidence of their effectiveness. ${ }^{46}$ As found in other regions of the world, the attitude that the abstinence model of drug treatment is of paramount importance persists and rejection of the concept of OST maintenance is widespread, despite opioid dependence being acknowledged as a chronic medical condition. ${ }^{47}$ As a result, it could be argued that this has been the major reason for reduced political will, financial under-investment and lack of commitment toward the scaling up of essential harm reduction interventions, including OST.

Advocacy for and funding of OST scale-up in the countries under review remains largely driven by UN agencies and the international donor community. Initial funding of and sustainable investment in harm reduction services, including OST, remains a perennial problem. Recent global studies have revealed over $90 \%$ of HIV-related harm reduction funds in low and middle income countries stem from international donors, and total funding remains inadequate. ${ }^{44}$ The cost of OST for individual recipients is prohibitive in many cases, and this greatly reduces the numbers of PWID in treatment. In Indonesia, while methadone could cost a client 1-2 UD Dollars (\$) per dose through a government service, an 8-12 mg dose of buprenorphine commonly costs 11-17 $\$$ through a private medical practitioner. As a result, many PWID can only afford to purchase an inadequate dose that proves ineffective and contributes towards ongoing injecting of illicit drugs.

Despite these problems, it is important to highlight progressive steps from Asian countries such as Malaysia and China, where governments strongly endorse OST and are expanding the OST programme nationwide. By 2009, China had 680 methadone clinics in 27 provinces with 242,000 patients (ever) enrolled, while Malaysia had 59 government facilities and nine private clinics dispensing methadone to 7065 registered clients, with an additional 10,000 clients receiving methadone through private practitioners. ${ }^{39,48}$ In 2011 Malaysia further expanded its methadone programme, with substantially more distribution sites: 168 public health clinics, 48 public hospitals, 24 general practitioners (GPs), 32 National Anti-Drug Agency sites, 18 prisons and two others. A cumulative 20,955 PWID have been registered in public facilities since 2006 and another 23,573 PWIDs are receiving MMT from
GPs. Due to the separate registration systems of private and public services, it is not possible to identify whether patients receiving methadone from private GPs were also registered with public facilities (Naning H., 2012; personal communication).

In all countries under review, the focus remains largely on the traditional treatment model of detoxification and rehabilitation despite strong evidence of recidivism, with rates often ranging from 60 $100 \% .{ }^{13,48}$ Despite the international evidence highlighting the broadranging health, social and economic benefits of $0 \mathrm{ST}^{49}$ a lack of indepth knowledge, awareness and education about OST among policymakers, community members, drug users and the health sector constrains the scaling up of OST. ${ }^{31,50,51}$ As found worldwide, one of the greatest obstacles to OST acceptance in the SEAR is limited acceptance and practice of evidence-based medicine associated with OST in the medical workforce. ${ }^{47}$

Research has shown that it is commonly perceived that providing OST is simply replacing one drug with another, despite evidence that methadone is superior to non-pharmacological methods in terms of client retention in treatment, reduced self-reported heroin use and both urine and hair analysis. ${ }^{52,53}$ In some parts of the world, including in some Asian countries, providing OST can be viewed as a failure to deal with the criminal behaviour of drug users. Consequently, the implementation of an abstinence-based model of treatment is still strongly advocated as the primary approach to address drug dependency. In addition, tensions continue between supply/demand reduction and harm reduction approaches, and impacts upon expansion of OST services. ${ }^{54}$

Highlighting an effective OST treatment model that builds upon local evidence can contribute towards expansion of drug treatment services for PWID. One aspect of effectiveness is to achieve an optimal dose of OST (usually greater than $60 \mathrm{mg}$ of methadone) that can lead to a decrease in the use of illicit drugs and ensure a higher retention rate and decrease in HIV risk behaviours. ${ }^{55}$ However, it is not uncommon practice for a lower dose to be prescribed for clients receiving OST in South-East Asia. For example, in Indonesia an integrated biological survey among PWID noted that most of those who received methadone in the past year were still injecting illicit opioids in the past week, and it was speculated that one reason for this was inadequate dosage. ${ }^{56}$

Doses of methadone of more than $60 \mathrm{mg}$ daily are recommended, with most clients requiring $60-120 \mathrm{mg}$ daily. ${ }^{57}$ In some countries under review, low-dose buprenorphine was common practice ( $<4 \mathrm{mg}$ daily). Recent buprenorphine guidelines in India (2009) recommend 4-8 mg as the optimal buprenorphine dose, ${ }^{32}$ despite international evidence recommending that people be stabilised on $8-16 \mathrm{mg}$ daily. ${ }^{57}$ Overall poor monitoring and evaluation of OST programmes exists in the countries under review and this does not allow local experiences to be translated into coherently managed knowledge about a program. As a consequence this impacts upon seeking ways to improve and expand coverage of the OST service.

\section{Discussion}

\section{Moving forward with scale-up of opioid substitution therapy}

In 2005, WHO added methadone and buprenorphine to the WHO Model List of Essential Medicines, and this endorsement provided high-level official support to advocate with the appropriate government ministries for the introduction and wider use of OST in treatment programmes. However, despite the official use of OST in all countries under review, specific policies for OST either do not exist or are too underdeveloped to have the desired impact. Many countries in the region need greater official acknowledgement of PWID and the role 
they play in the HIV epidemic and respond according to the epidemiological and national context. ${ }^{58,59}$

A national policy would assist in establishing a set of standards for OST provision and address the needs of politicians, health administrators, program managers, clinicians and OST recipients. Such policies should reflect a national agreement about the important strategic role of OST in reducing the adverse health, social and economic consequences of drug use, and outline key objectives and procedures. Evidence of the benefits of OST in all countries under review warrants increased highlevel support for and expansion of OST, as has occurred in China. ${ }^{39}$

Criminalisation of drug use continues to restrict the wider utilisation of OST. As a result it is critically important to increase the law enforcement sector's understanding of OST, and to advocate for it to endorse the expansion of OST. National Working Groups or Task Forces on harm reduction, with a high priority on OST, are similarly important, requiring participation of senior officials from health, police, academia and representatives of civil society for maximum benefit.

Despite an incremental growth in knowledge of OST since its introduction in various countries of South-East Asia, building staff and institutional capacity remains critically important. The skills and knowledge of staff working on drug dependency and OST is often lacking, and consequently regular training programmes are necessary. Poly-drug use is widespread, with opioids often being mixed with benzodiazapines and other pharmaceuticals; many clinical staff are uncertain as to how to address these issues. Training programmes facilitate sustainable expansion and improved quality of OST services, and encourage long-term commitment towards OST treatment patients and PWID in general. Of equal importance is the need to conduct regular monitoring and evaluation of OST programmes at national and local level. Data identifying both effective approaches and difficulties inform policymakers and other stakeholders about how to improve quality and continue expansion of OST services.

Correspondence:Peter Higgs, National Drug Research Institute-Melbourne, Suite 6, 19-35 Gertrude Street, Fitzroy Vic 3065, Australia.

Tel. +61.390.792.202.

E-mail: peter.higgs@curtin.edu.au

E-mail: garyangola@yahoo.com.au

Key words: methadone, Southeastern Asia, illicit drugs, policy.

Acknowledgements: the authors would like to thank the WHO SEARO country staff in India, Indonesia, Myanmar, Nepal and Thailand for their assistance with data collection and guidance towards people involved in the dispensing of opioid substitution therapy. The authors are grateful to Dr Rajesh Kumar and Dr Tasnim Azim for providing updated information about OST in India and Bangladesh. Peter Higgs is supported by an early career research fellowship from Curtin University. The National Drug Research Institute at Curtin University is supported by funding from the Australian Government under the Substance Misuse Prevention and Service Improvement Grants Fund.

Contributions: GR, conducted the research for this manuscript. GR, MS, PH, contributed to the analysis and interpretation of the findings and the drafting and editing of the manuscript.

Conflict of interests: the authors declare no potential conflict of interests.

Received for publication:17 September 2013.

Accepted for publication: 17 February 2014.

(C) Copyright G. Reid et al., 2014

Licensee PAGEPress, Italy

Journal of Public Health Research 2014; 3:204

doi:10.4081/jphr.2014.204

This work is licensed under a Creative Commons Attribution NonCommercial 3.0 License (CC BY-NC 3.0).

\section{References}

1. Mathers B, Degenhardt L, Phillips B, et al. Global epidemiology of injecting drug use and HIV among people who inject drugs: a systematic review. Lancet 2008;372:1733-45.

2. Mathers BM, Degenhardt L, Ali H, et al. HIV prevention, treatment, and care services for people who inject drugs: a systematic review of global, regional, and national coverage. Lancet 2010; 375:1014-28.

3. WHO HIV/AIDS programme. Towards universal access by 2010: how WHO is working with countries to scale-up HIV prevention, treatment, care and support. Geneva: WHO; 2006.

4. WHO South-East Asia Regional Office (SEAR0). Report on people who inject drugs in the South-East Asia region. New Delhi: WHO SEAR0; 2010.

5. WHO South-East Asia Regional Office. Progress report HIV/AIDS in the South-East Asia Region. New Delhi: WHO SEARO; 2009.

6. Family Health International, Nepal. Integrated biological and behavioural survey among injecting drug users in Kathmandu valley. Kathmandu, Nepal; 2002.

7. Family Health International, Nepal. Integrated biological and behavioural survey among injecting drug users in Kathmandu. Kathmandu, Nepal; 2009

8. NCASC. Integrated biological and behavioural survey among injecting drug users in Kathmandu. Round 5. 2011. Available from: http:/www.ncasc.gov.np/uploaded/publication/Reports/IBBS/IDUs/I BBS_IDUs_Pokhara_Final_Report_2011.pdf

9. Azim T, Khan SI, Nahar Q, et al. Twenty years of HIV in Bangladesh: experiences and way forward. Dhaka, Bangladesh, World Bank/ UNAIDS. 2009. Available from: http//www.hnpinfobangladesh.com/ docs/di_220_Consolidated\%20Report\%20Nov\%2030\%20final.pdf

10. National AIDS Control Organization (NACO). Injecting drug use strategy report for NACP IV planning. New Delhi: NACO; 2011.

11. WHO. A strategy to halt and reverse the HIV epidemic among people who inject drugs in Asia and the Pacific 2010-2015. Available from: http://www.who.int/hiv/pub/idu/searo_strategy/en/

12. Sharma M, Oppenheimer E, Saidel T, New Delhi. A situation update on HIV epidemics among people who inject drugs and national responses in South-East Asia Region. AIDS 2009;23:1405-13.

13. Devaney M, Reid G, Baldwin S. Situational analysis of drug issues and responses in the Asia Pacific Region. Prepared for the Australian National Council on Drugs, Asia Pacific Drug Issues Committee. Melbourne: Centre for Harm Reduction, Burnet Institute and Turning Point Alcohol and Drug Centre; 2006.

14. WHO, UNODC, UNAIDS. Technical guide for countries to set targets for HIV prevention, treatment and care for injecting drug users. Geneva: WHO; 2009.

15. Degenhardt L, Mathers B, Vickerman P, et al. Prevention of HIV infection for people who inject drugs: why individual, structural, and combination approaches are needed. Lancet 2010;376:285-301.

16. Ward J, Mattick R., Hall W, eds. Methadone maintenance treatment and other opioid replacement therapies. Amsterdam: Harwood Academic Publishers; 1998.

17. Heimer R, Bray S, Burris S, et al. Structural interventions to improve opiate maintenance. Int J Drug Policy 2002;13:103-11.

18. Lawrinson P, Ali R, Chiamwongpaet ABS, et al. Key findings from the WHO collaborative study on substitution therapy for opioid dependence and HIV/AIDS. Addiction 2008;103:1484-92.

19. Tenore P. Psychotherapeutic benefits of opioid agonist therapy. J Addict Dis 2008;27:49-65.

20. Hendrée JE, Haug N, Silverman K, et al. The effectiveness of incentives in enhancing treatment attendance and drug abstinence in methadone-maintained pregnant women. Drug Alcohol Depend 2001;61:297-306. 
21. Burrows D, Panda S, Crofts N. HIV/AIDS prevention among injecting drug users in Kathmandu Valley. Melbourne: Centre of Harm Reduction; 2001.

22. Samson L, Singh R, Barua P. Qualitative research as a means of intervention development. Addict Res Theory 2001;9:587-99.

23. Kumar MS, Mudaliar S, Daniels D. Injection drug use and HIV infection in South Asia: opportunities and challenges for prevention efforts. Proceedings of the Research Network on HIV prevention in drug using populations second annual meeting. 28-29 August 1999, Atlanta, Georgia.

24. Kumar MS, Agrawal A. Scale-up of opioid substitution therapy in India: opportunities and challenges. Int J Drug Policy 2012;23:169-70.

25. Legislative Council Secretariat Methadone Treatment Programmes in Hong Kong and Selected Countries, 1996. Research and library services division, Hong Kong. Available from: http://www.legco. gov.hk/yr97-98/english/sec/library/956rp12.pdf

26. Smith B, Hayter J. Opioid situation treatment in Thailand: situation and training needs analysis turning point, Fitzroy, Australia, 2008. Available from: http://mmt.niramit.asia/downloads/OST\% 20TNA\%20Thailand\%20Country\%20Chapter\%20-\%20Turning\% 20Point\%202008.pdf

27. National Narcotics Board. Indonesian Country Report: $23^{\text {rd }}$ meeting of the ASEAN senior officials on drug matters. Kuala Lumpur: National Narcotics Board; 2002.

28. Moore, T. HIV and injecting drug use in Indonesia. Jakarta: World Health Organization, Regional Office for Southeast Asia, Country Office for Indonesia; 2003.

29. Mesquita F, Winarso I, Atmosukarto II, et al. Public health the leading force of the Indonesian response to the HIV/AIDS crisis among people who inject drugs. Harm Reduct J 2007;4:9.

30. Bergenstrom A, Andreeva V, Reddy A. Overview of epidemiology of injection drug use and HIV in Asia. International Harm Reduction Conference, The Values of Harm Reduction: Vilnius 2013. Available from: http://www.unodc.org/documents/southeastasiaandpacific// poster/Regional_overview_of_IDU_and_HIV_in_Asia_final_3_Ju n_2013.pdf

31. Chengappa MN, Rao R, Suresh Kumar M. The development of methadone maintenance treatment in the Maldives. Int $\mathrm{J}$ Drug Policy 2013;24:164-5.

32. Burns K, Shrestha RP. Prevention of transmission of HIV among drug users in SAARC countries, phase II 2007-12, mid-term review. Geneva: UNODC, UNAIDS, WHO; 2010

33. Kumar S, Natale RD, Langkham B, et al. Opioid substitution treatment with sublingual buprenorphine in Manipur and Nagaland in Northeast India: what has been established needs to be continued and expanded. Harm Reduct J 2009;6:4.

34. UNGASS, National AIDS Prevention and Alleviation Committee. UNGASS country progress report, Thailand. Reporting period: january 2008 - december 2009. Bangkok: UNGASS; 2010.

35. Sarasvita R. Review of opioid substitution therapy in Indonesia. Presentation as part of OST programmes review in Indonesia, WHO and substance abuse management \& prevention. Jakarta: Ministry of Health Republic of Indonesia; 2011.

36. The Global Fund to Fight AIDS, Tuberculosis and Malaria. Myanmar. Available from: http://portfolio.theglobalfund.org/en/ Country/Index/MMR

37. WHO. Guidelines on methadone therapy and treatment of drug dependence in Myanmar. Available from: https:/apps.searo.who. int/pds_docs/B4940.pdf

38. Mortimore G, Stimson G. A process and systems evaluation of the drug treatment and rehabilitation services in the Maldives. Available from: http://www-wds.worldbank.org/external/default/ WDSContentServer/WDSP/IB/2012/07/19/000333037_20120719011 541/Rendered/PDF/712880WP0P113500January020110GM0GS.pdf
39. Yin W, Hao Y, Sun X, et al. Scaling up the national methadone maintenance treatment program in China: achievements and challenge. Int J Epidemiol 2010;39:29-37.

40. Chan KY, Stoové M, Reidpath D. Stigma, social reciprocity and exclusion of HIV/AIDS patients with illicit drug histories: a study of Thai nurses' attitudes. Harm Reduct J 2008;5:28.

41. Young M, Stuber J, Ahern J, Galea S. Interpersonal discrimination and the health of illicit drug users. Am J Drug Alcohol Abuse 2005;31:371-91.

42. UK Drug Policy Commission. Getting serious about stigma: the problem with stigmatizing drug users; an overview. UK Drug Policy Commission; 2010. Available from: http:/www.ukdpc.org.uk/publication/getting-serious-about-stigma-problem-stigmatising-drug-users/

43. Friedman SR, Des Jarlais DC. HIV among drug injectors: the epidemic and the response. AIDS Care 1991;3:239-50.

44. Stimson, G. AIDS and injecting drug use in the United Kingdom, 1987-1993: the policy response and the prevention of the epidemic. Soc Sci Med 1995;41:699-716.

45. Csete J. Dube S. An inappropriate tool: criminal law and HIV in Asia. AIDS 2010;24(Supp 3):S80-5.

46. Amon JJ, Pearshouse R, Cohen JE, Schleifer R. Compulsory drug detention in East and Southeast Asia: evolving government, UN and donor responses. Int J Drug Policy 2014;25:13-20.

47. Newman R. Opioid maintenance treatment: a glass half full but also half empty! Available from: http://www.indro-online.de/ Newman2011.pdf

48. Kamarulzaman A. Impact of HIV prevention programs on drug users in Malaysia. J Acqir Immune Defic Syndr 2009;52:S17-9.

48. Reid G, Crofts N. Rapid assessment of drug use and HIV vulnerability in south-east and east Asia. Int J Drug Policy 2000;11:113-4.

49. Amato L, Davoli M, Perucci CA, et al. An overview of systematic reviews of the effectiveness of opiate maintenance therapies: available evidence to inform clinical practice and research. J Subst Abuse Treat 2005;28:321-9.

50. Latypov A. Opioid substitution therapy in Tajikistan: another perpetual pilot? Int J Drug Policy 2010;21:407-10.

51. Stancliff S, Myers JE, Steiner S, Drucker E. Beliefs about methadone in an inner-city methadone clinic. J Urban Health 2002;79:571-8

52. Beyrer C, Malinowska-Sempruch K, Kamarulzaman A, Strathdee S. 12 myths about HIV/AIDS and people who use drugs. Lancet 2010;376:208-11.

53. Mattick RP, Breen C, Kimber J, Davoli M. Methadone maintenance therapy versus no opioid replacement therapy for opioid dependence. Cochrane Database Syst Rev 2009;3:CD002209.

54. UNAIDS, UNDCP. Drug use and HIV vulnerability: policy research study in Asia. Regional Centre for East Asia and the Pacific. Bangkok: UNAIDS, UNDCP; 2000.

55. Marsch LA. The efficacy of methadone maintenance interventions in reducing illicit opiate use, HIV risk behaviour and criminality: a meta-analysis. Addiction 1988;93:515-32.

56. Integrated Biological Behavioural Surveillance (IBBS). Indonesia, injecting drug use. Jakarta: IBBS; 2007.

57. WHO. Operational guidelines for the management of opioid dependence in the South-East Asia Region. New Delhi: WHO, Regional Office for South-East Asia; 2008.

58. Herget G. Methadone and buprenorphine added to the WHO list of essential medicines. HIVAIDS Policy Law Rev 2005;10:23-4.

59. United Nations General Assembly. Implementation of the declaration of commitment on HIV/AIDS and the political declaration on HIV/AIDS. Available from: http://australia-unsc.gov.au/2013/06/ implementation-of-the-declaration-of-commitment-on-hivaidsand-the-political-declaration-on-hivaids/ 